\title{
Effect of Heat Treatment Conditions on Shape Control of Large-sized Elongated MnS Inclusions in Resulfurized Free-cutting Steels
}

\author{
Xiaojing SHAO, Xinhua WANG, Min JIANG, Wanjun WANG and Fuxiang HUANG \\ School of Metallurgical and Ecological Engineering, University of Science and Technology Beijing, Beijing, 100083 China. \\ E-mail: shaoxiaojing2008@yahoo.com.cn
}

(Received on April 28, 2011; accepted on June 15, 2011)

\begin{abstract}
Effect of heat treatment conditions on shape evolution of large-sized elongated MnS inclusions in resulfurized free-cutting rolled steel has been investigated using confocal scanning laser microscope and $\mathrm{Si}_{2} \mathrm{Mo}$ resistance furnace. The results show that the heating rate, soaking temperature and soaking time impose significant effects upon shape profiles of elongated MnS. The split of slender MnS was oberved in continuous heating with heating rate in the range of $0.5-2 \mathrm{~K} / \mathrm{s}$. In addition, split degree of $\mathrm{MnS}$ indicated a negative relation with the rise of heating rate. As a result, separation of elongated MnS was not observed at the heating rate of $6 \mathrm{~K} / \mathrm{s}$. During soaking experiments, there was no remarkable shape change for $\mathrm{MnS}$ at temperature lower than $1073 \mathrm{~K}$. While the elongated MnS splited up and spheroidized obviously at $1473 \mathrm{~K}$. Correspondingly, number density of inclusions increased while mean length reduced as the soaking time increased from $1 \mathrm{~h}$ to $4 \mathrm{~h}$ at $1473 \mathrm{~K}$. Significant shape change from slender to spindlelike or spherical was identified only when the soaking time exceeds $3 \mathrm{~h}$ or $4 \mathrm{~h}$. Based on the Gibbs Thompson relation and the obtained experimental results, mechanism of shape evolution of MnS inclusions was discussed and morphology evolution of MnS was divided into three major steps: (1) first, the shrinkage occurred in the longitudinal direction at the beginning of heating process, (2) expansion and contraction in radial direction followed after the shrinkage which caused the split of slender MnS; (3) eventually, the spherical particles emerged from the split parts.
\end{abstract}

KEY WORDS: large-sized elongated MnS inclusions; in-situ observation; resulfurized free-cutting steel.

\section{Introduction}

$\mathrm{MnS}$ is a common type of non-metallic inclusions in steel, which is of good deformability during rolling. As elongated $\mathrm{MnS}$ inclusions along rolling direction often cause poor transverse toughness and stress corrosion cracking of medium plates, they are commonly considered to be harmful thus are removed as impurities. However, different from most steel products, some steel grades such as free cutting steel, hot forging steel, etc. must contain certain amount of $\mathrm{MnS}$ inclusions so as to have good machinability. For getting better property of the steel, MnS inclusions must be strictly controlled to be small, uniformly distributed, and shaped like spindles or spheres.

Shape and size variation of $\mathrm{MnS}$ inclusions by heat treatment have been discussed in the previous reports. Flowers ${ }^{1)}$ first studied $\mathrm{MnS}$ inclusion in $\mathrm{Fe}-3 \% \mathrm{Si}$ alloy with respect to texture formation. After that, Gnanamuthu ${ }^{2}$ concerned with different types of $\mathrm{MnS}$ and found all $\mathrm{MnS}$ inclusions finally changed to polyhedron after long time soaking. Murty ${ }^{3-5}$ ) found there were three stages for the evolution of elongated type II and III MnS in high sulfur steel: (1) cylinderization (2) ovulation (3) coarsening. Then Mcfarland ${ }^{6}$ paid attention to the spheroidization of type II MnS with the homog- enization. Nishida ${ }^{7)}$ focused on MnS inclusions in low sulfur rolled steel and found these particles started to spherizate at $873 \mathrm{~K}$. We also have lately investigated the behavior of $\mathrm{MnS}$ inclusions in hot forging casting steel through various heat treatments. $^{8,9)}$ However, direct observation on the shape change of elongated $\mathrm{MnS}$ in solid steel have not been reported yet.

In present study, confocal scanning laser microscope (CSLM) was first used to in-situ observe the shape evolution of large-sized elongated $\mathrm{MnS}$ inclusions in resulfurized free-cutting steels. The effects of heating rate, soaking temperature and soaking time on shape control of largesized elongated $\mathrm{MnS}$ were systematically investigated with methods of in-situ observation by CSLM and iso-thermal treatments in electrical resistance furnace. And the mechanism why these large-sized elongated MnS could break up during heating was also analyzed. The research can provide a theoretical guidance for the design of thermal parameters in heat treatment of resulfurized free-cutting steels.

\section{Experimental Procedures}

Steel materials used in the experiments were commercial rolled steels of resulfurized free-cutting steel. Major chemical 
compositions (mass\%) are determined as Carbon of 0.086, Silicon less than 0.01, Manganese of 1.02 and Sulfur of 0.32 .

A typical confocal scanning laser microscope (VL2000DX-SVF17SP) was used for in-situ observation of shape evolution of large-sized elongated $\mathrm{MnS}$ inclusions during heating. The samples were $7.5 \mathrm{~mm}$ in diameter, $4 \mathrm{~mm}$ in height and mirror polished before the experiments. In the in-situ observation, the sample was continuously heated to desired temperature at an even rate in an alumina crucible under high purity Ar atmosphere. Two series of experiments were carried out to elucidate the effects of heating rate and soaking temperature on the evolution of $\mathrm{MnS}$, respectively. In heating rate experiments, the samples were heated at the rate of $0.5 \mathrm{~K} / \mathrm{s}, 1 \mathrm{~K} / \mathrm{s}, 2 \mathrm{~K} / \mathrm{s}, 6 \mathrm{~K} / \mathrm{s}$ and $10 \mathrm{~K} / \mathrm{s}$, respectively to $1463 \mathrm{~K}$. In soaking temperature experiments, the sample was heated to $873 \mathrm{~K}, 1073 \mathrm{~K}, 1273 \mathrm{~K}$ and $1473 \mathrm{~K}$ at a rate of $6 \mathrm{~K} / \mathrm{s}$ and held for 300 seconds, respectively. After the experiments, characteristics like composition and shape of MnS inclusions were analyzed by SEM (JSM-6480LV).

Experiments were carried out in a vertical type $\mathrm{Si}_{2} \mathrm{Mo}$ resistance furnace to find the influence of soaking time on $\mathrm{MnS}$. In each experiment, the furnace was first heated to $1473 \mathrm{~K}$ under Ar atmosphere. Then a sample with a thickness of $1.2 \mathrm{~mm}$ was hanged by a steel wire from the top cover and set at the even temperature zone of the furnace. After soaked for a predetermined period of time, the sample was quickly dropped into the ice water. The soaking time was controlled to be $1 \mathrm{~h}, 2 \mathrm{~h}, 3 \mathrm{~h}$ and $4 \mathrm{~h}$, respectively. All the obtained samples were mounted and mirror polished. Size characters of MnS inclusions in about $20 \mathrm{~mm}^{2}$ in each sample were analyzed by optical microscope (LEICA DM6000).

\section{Results}

\subsection{Non-metallic Inclusions in Rolled Steel}

Initial morphology, composition and distribution of inclusions in rolled materials were shown in Fig. 1. Inclusions were mainly $\mathrm{MnS}$ of slender shape (Length/Width>3), elongated along the rolling direction. Lengths of 8735 nonmetallic inclusions in $20.46 \mathrm{~mm}^{2}$ were measured (see Table 1). It was found that large-sized inclusions are abundant, with a density of $15.06 / \mathrm{mm}^{2}$ for MnS larger than $40 \mu \mathrm{m}$.

\subsection{In-situ Observation}

Figure 2 showed the shape evolution of slender $\mathrm{MnS}$ at the heating rate of $0.5 \mathrm{~K} / \mathrm{s}$. The original size of the $\mathrm{MnS}$ was about $86.3 \mu \mathrm{m}$ in length and 91.3 in aspect ratio. Division of $\mathrm{MnS}$ was observed in the continuous heating. When temperature rose to about $1073 \mathrm{~K}$, single $\mathrm{MnS}$ inclusions began to divide into two particles. At $1373 \mathrm{~K}$, there are nine split particles. As the temperature increased, lengths of split MnS reduced, and shapes changed to spindles. The aspect ratios of initial MnS and split MnS particles at different temperatures were shown in Fig. 3.

Table 1. Number density of MnS inclusions at different length distributions.

\begin{tabular}{lcccccc}
\hline Distribution, $\mu \mathrm{m}$ & $5-20$ & $20-40$ & $40-60$ & $60-80$ & $80-100$ & $>100$ \\
\hline Density, $/ \mathrm{mm}^{2}$ & 344.87 & 67.01 & 10.46 & 2.69 & 1.08 & 0.83 \\
\hline
\end{tabular}
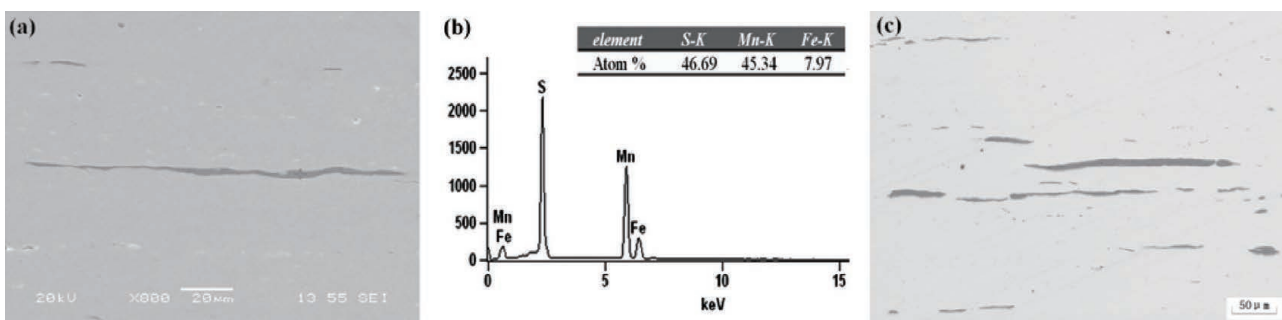

Fig. 1. Morphology and composition of typical inclusions in steel (a) SEM image (b) EDS result (c) OM image.

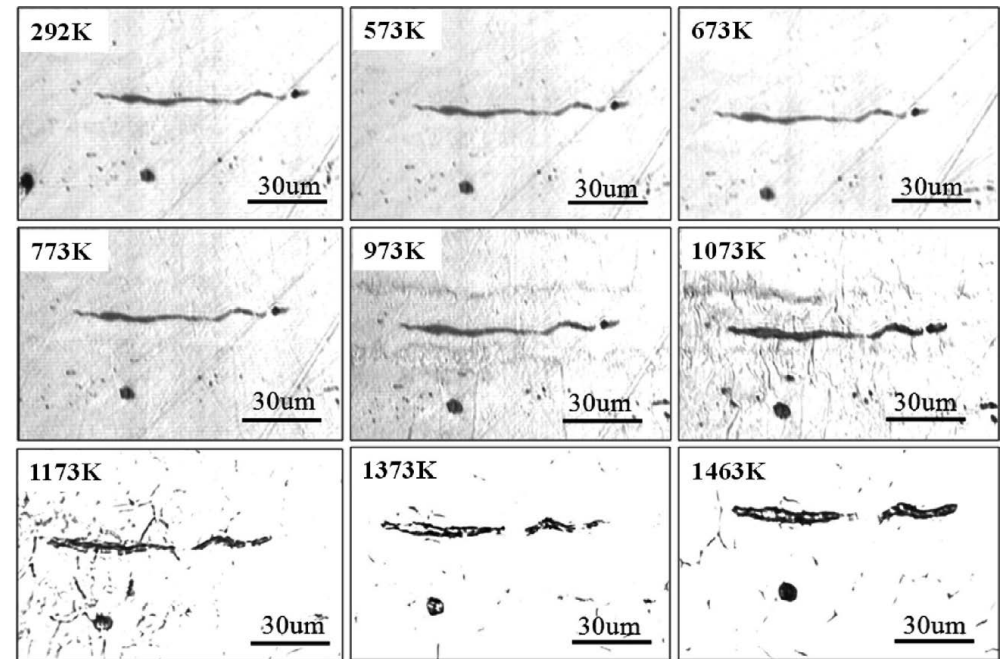

Fig. 2. Shape evolution of large-sized elongated $\mathrm{MnS}$ inclusion at the heating rate of $0.5 \mathrm{~K} / \mathrm{s}$. 
After the heating, MnS inclusions were observed by SEM. Two types of divisions were identified: (1) For type A division, the gap between two split $\mathrm{MnS}$ inclusions was fully filled with Fe atoms, as shown in Fig. 4(a). (2) For type B division, the gap was void from the picture in Fig. 4(b). Both types of divisions for $\mathrm{MnS}$ can be observed in the above in-situ observation experiment at $1463 \mathrm{~K}$, as shown by Fig. 4(c). It's found that type A division occurred twice for $\mathrm{MnS}$ at $1463 \mathrm{~K}$. Meanwhile, type B division happened twelve times. And total 15 split particles formed eventually.

From the above analysis, we knew that large-sized elongated $\mathrm{MnS}$ divided into 15 particles at $1463 \mathrm{~K}$. In order to get detailed information on shape evolution of $\mathrm{MnS}$, the length and the width of each split $\mathrm{MnS}$ were analysed. And the length and the width of initial slender $\mathrm{MnS}$ in corresponding positions were also measured. First, intervals were divided according to the length of split $\mathrm{MnS}$ at $1463 \mathrm{~K}$, as shown in Fig. 5(a). Then, same intervals were made for original slender MnS at $292 \mathrm{~K}$, as shown in Fig. 5(b). Lastly, the length and the width of $\mathrm{MnS}$ in each interval were analyzed, as shown in Figs. 5(c) 5(d).

Figures 5(c) 5(d) showed that the length and the width of $\mathrm{MnS}$ changed significantly. For the length in the same interval, $\mathrm{MnS}$ at $1463 \mathrm{~K}$ were smaller than the ones at $292 \mathrm{~K}$. For the width, some were larger at $1463 \mathrm{~K}$, the others are bigger at $292 \mathrm{~K}$. It's indicated that shape variations of $\mathrm{MnS}$ inclusions were as follows: (1) The shrinkage occured in length direction (axial contraction). (2) Expansion and contraction happened in radial direction, which finally caused the break-up of slender MnS. Numerical simulation of shape evolution for a rod has been done by Nichol et $a l .{ }^{10,11)}$ It's found that for the rod $(\mathrm{L} / \mathrm{D}=7.19)$, the length

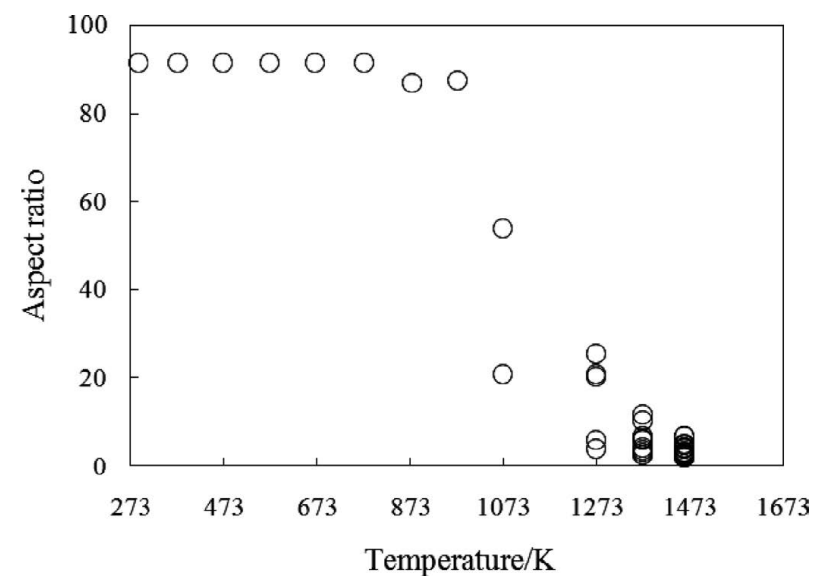

Fig. 3. Aspect ratios of $\mathrm{MnS}$ at differenent temperatures. recedes toward each other. Simultaneously, Bulges near the two ends and necking in the middle occur, which finally form two egg-shaped particles. Shape evolution observed in present study is basically in agreement with Nichol.

\subsection{Effect of Heating Rate}

In order to investigate the effect of heating rate on shape evolution of large-sized elongated $\mathrm{MnS}$, samples were heated at $1 \mathrm{~K} / \mathrm{s}, 2 \mathrm{~K} / \mathrm{s}, 6 \mathrm{~K} / \mathrm{s}$ and $10 \mathrm{~K} / \mathrm{s}$ respectively. The maximum temperature was $1463 \mathrm{~K}$, at which slender $\mathrm{MnS}$ in casting slab had been observed to split in our previous work. ${ }^{12)}$ Besides, $1463 \mathrm{~K}$ is still in the proper temperature range for heat treament in actual production process. Images were listed only at $300 \mathrm{~K}, 1073 \mathrm{~K}$ and $1463 \mathrm{~K}$ for each heating rate (See Fig. 6). Investigated $\mathrm{MnS}$ inclusions were indicated by arrows. Images at $0.5 \mathrm{~K} / \mathrm{s}$ were shown in Fig. 2 . It's found that $\mathrm{MnS}$ split remarkably at $0.5 \mathrm{~K} / \mathrm{s}$ and $1 \mathrm{~K} / \mathrm{s}$. When the heating rate increased to $2 \mathrm{~K} / \mathrm{s}$, splitting degree reduced. There were no obvious changes for $\mathrm{MnS}$ at $6 \mathrm{~K} / \mathrm{s}$ and $10 \mathrm{~K} / \mathrm{s}$.

Figure 7 showed aspect ratios and the number of split $\mathrm{MnS}$ at different heating rates. When the heating rate decreased from $2 \mathrm{~K} / \mathrm{s}$ to $0.5 \mathrm{~K} / \mathrm{s}$, the number of split $\mathrm{MnS}$ increased from 4 to 14 and corresponding aspect ratios sharply reduced.

Shape changes of MnS could be indicated by the change rate of mean aspect ratio (CR for short), which was calculated by Eq. (1). As shown in Fig. 8, the change rate of mean aspect ratio reduced with an increasing of heating rate. It's
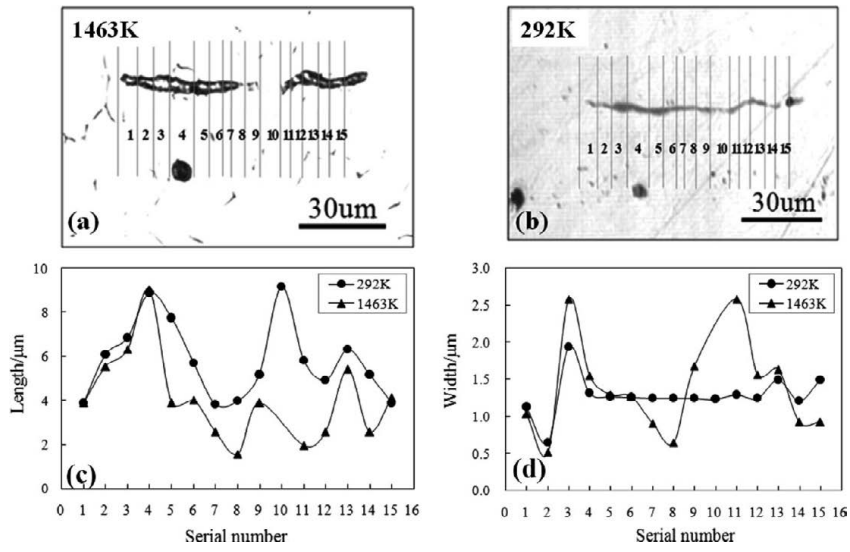

Fig. 5. Same intervals in images of $1463 \mathrm{~K}$ and $292 \mathrm{~K}$ and size characters of $\mathrm{MnS}$ in each interval (a) Interval-division of split MnS in the field of $1463 \mathrm{~K}$ (b) Same intervals divided in the field of $292 \mathrm{~K}$ (c) Length of MnS in each interval (d) Width of MnS in each interval.
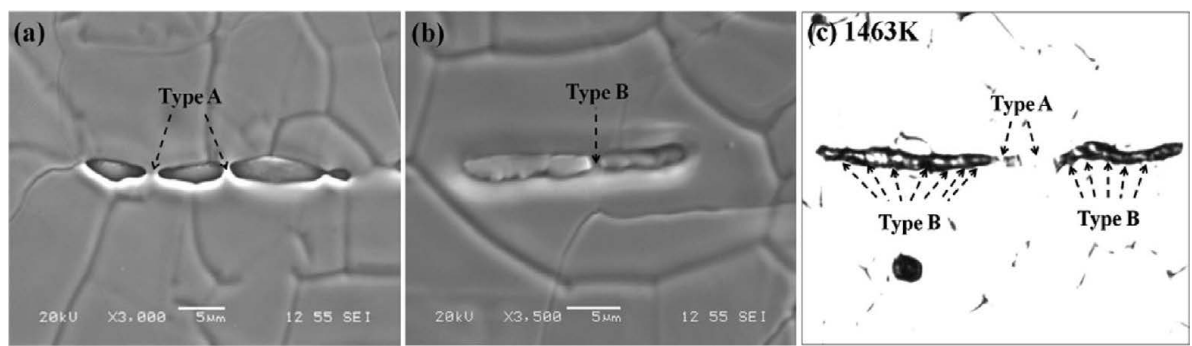

Fig. 4. SEM images of typical MnS after heating and enlarged photo of split MnS at $1463 \mathrm{~K}$ in in-situ observation experiment. 


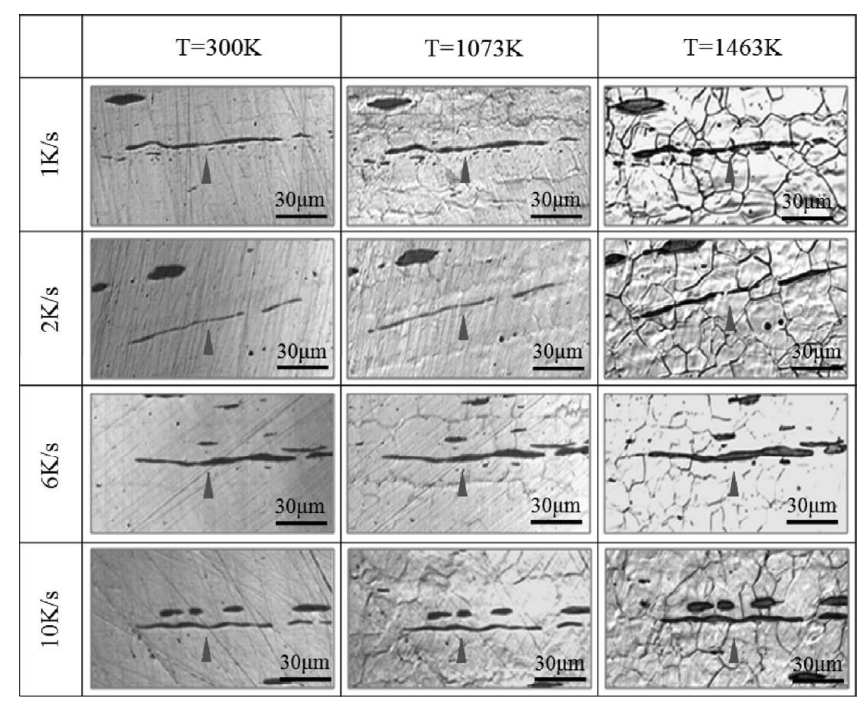

Fig. 6. In-situ observation of shape evolution of large-sized elongated $\mathrm{MnS}$ at different heating rate.

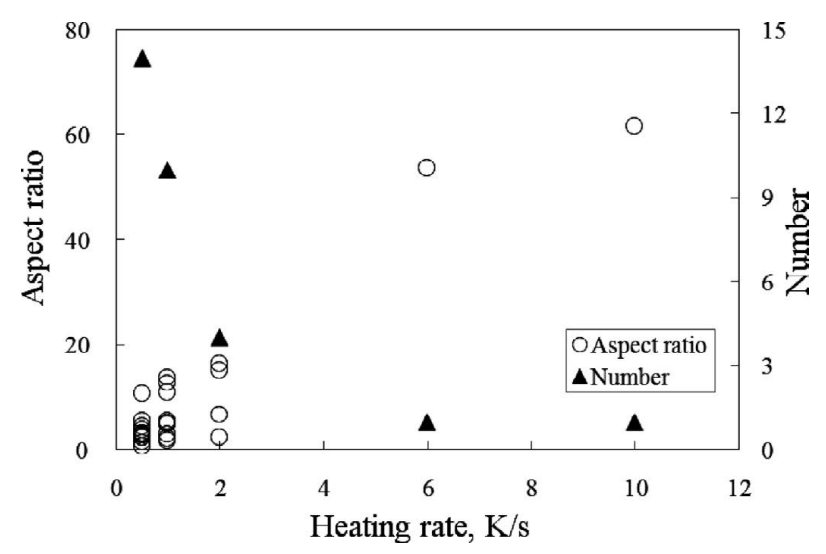

Fig. 7. Aspect ratios and the number of split MnS vs heating rate.

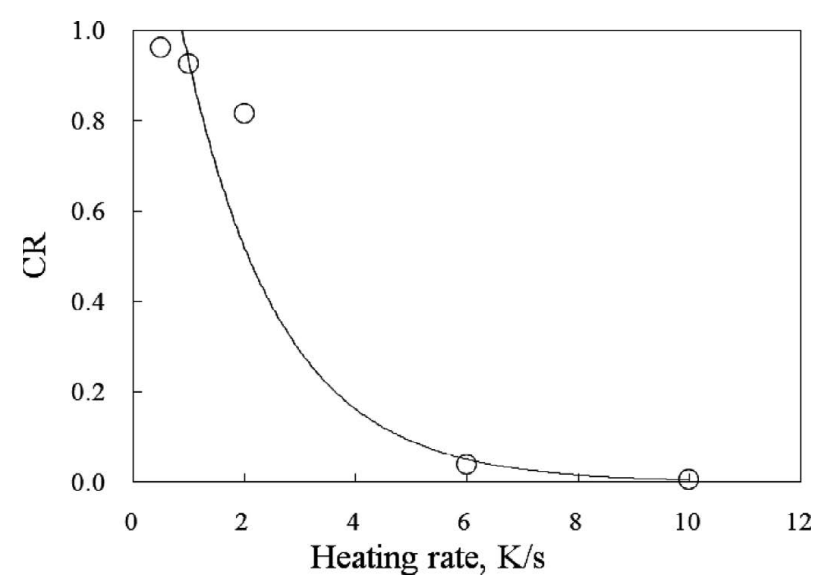

Fig. 8. Change rate of mean aspect ratio of MnS vs heating rate.

found that rapid heating is not beneficial to the break-up of large-sized elongated $\mathrm{MnS}$.

$$
\mathrm{CR}=\frac{(L / W)_{0}-(\overline{L / W})}{(L / W)_{0}}
$$

Where CR means change rate of mean aspect ratio, $L$ is length, $W$ is width, $(L / W)_{0}$ is initial aspect ratio of the inclusion, $\overline{L / W}$ is mean aspect ratio of split inclusions.

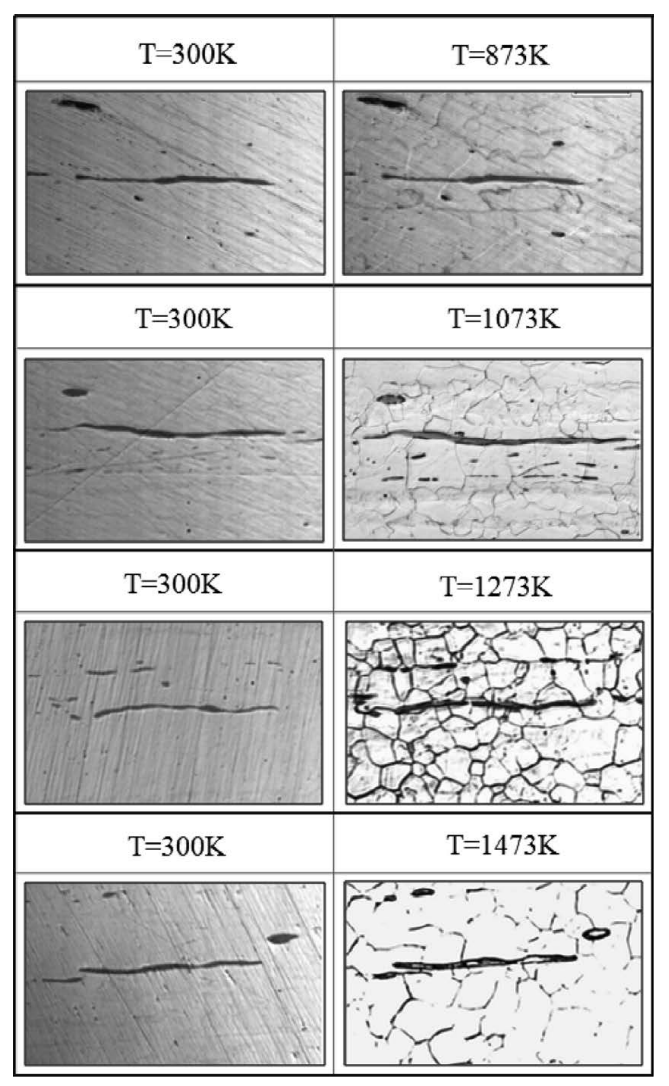

Fig. 9. In-situ observation of shape evolution of large-sized elongated $\mathrm{MnS}$ at different soaking temperature.

\subsection{Effect of Soaking Temperature}

In this part of experiments, soaking time and heating rate were chosen intentionally. From above experiments, it had been known that the heating rate of $6 \mathrm{~K} / \mathrm{s}$ had slight effect on slender MnS during continuous heating process. Therefore, this heating rate was chosen to investigate the effect of soaking temperature on shape change of $\mathrm{MnS}$ while favored diminishing interference of heating rate. Influence of phase transformation on $\mathrm{MnS}$ was also taken into accounted by varied soaking temperatures at $873 \mathrm{~K}(\alpha$-Fe $), 1073 \mathrm{~K}(\alpha+\gamma)$, $1273 \mathrm{~K}(\gamma-\mathrm{Fe})$ and $1473 \mathrm{~K}(\gamma-\mathrm{Fe})$, respectively, as diffusion coefficient of $\mathrm{Mn}$ and $\mathrm{S}$ atoms in $\alpha$-Fe is higher than in $\gamma$ $\mathrm{Fe}$ at the same temperature. ${ }^{13,14)}$ In view of soaking time, it had been found that $300 \mathrm{~s}$ was enough for the separation of elongated $\mathrm{MnS}$ and longer soaking time may affect the diffusions of $\mathrm{Mn}$ and $\mathrm{S}$ in turn which is not good to diminish effect of soaking time here. Hence, a soaking time of about $300 \mathrm{~s}$ was chosen.

Figure 9 showed $\mathrm{MnS}$ inclusions at $300 \mathrm{~K}$ and at desired temperatures for 300 s. Sizes characters of original MnS particles were similar in four expriments. Their lengths were $83.65,85.49,108.74$ and $119.76 \mu \mathrm{m}$, respectively and widths were $2.32,1.66,2.80$ and $3.67 \mu \mathrm{m}$, respectively. Aspect ratios of split $\mathrm{MnS}$ at desired temperatures were shown in Fig. 10. At $873 \mathrm{~K}$ and $1073 \mathrm{~K}, \mathrm{MnS}$ could not break up. When soaking temperature rose to $1273 \mathrm{~K}$, initial single MnS split to five particles. However, aspect ratios of the two of these five split MnS were still large, which were 24.79 and 22.33. At $1473 \mathrm{~K}$, the number of splitting $\mathrm{MnS}$ increased to six and aspect ratios reduced.

Shape change of $\mathrm{MnS}$ can be indicated by the change rate 


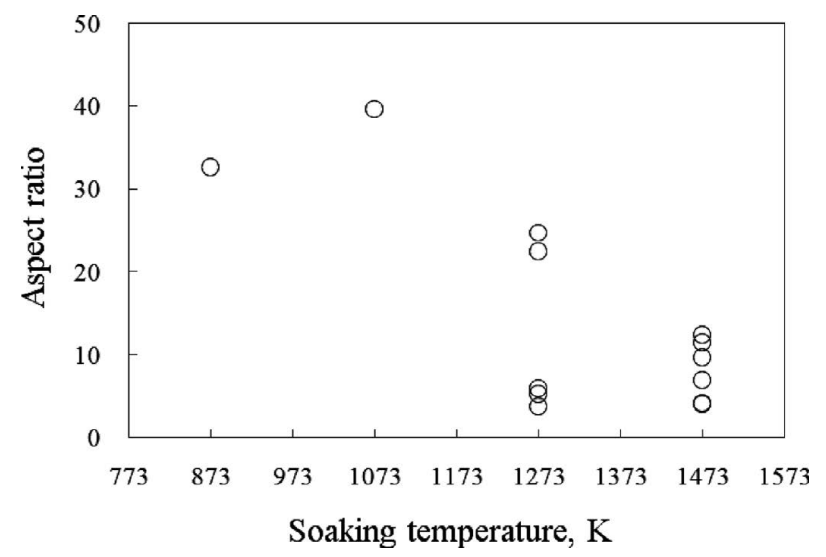

Fig. 10. Aspect ratios of split $\mathrm{MnS} v s$ soaking temperature.

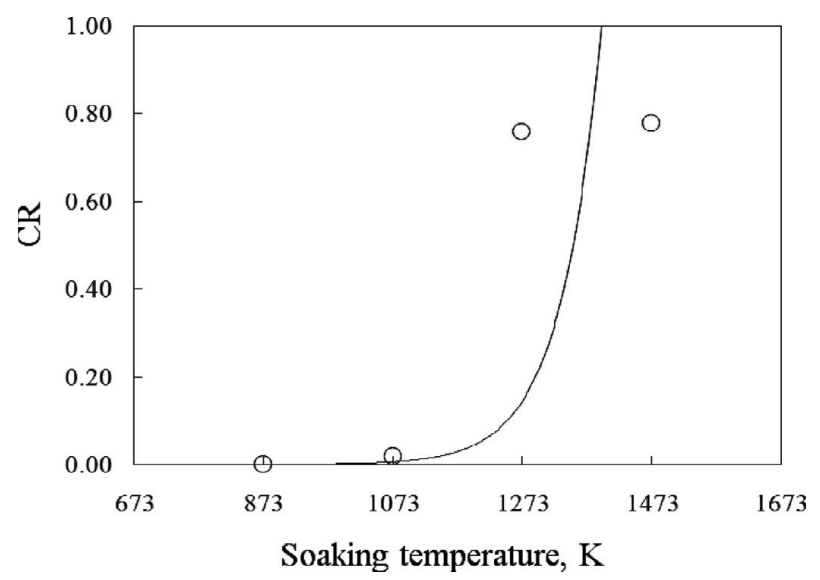

Fig. 11. Change rate of mean aspect ratio of $\mathrm{MnS} v s$ soaking temperature.

of mean aspect ratio, which was calculated by Eq. (1). As shown in Fig. 11, the change rate of mean aspect ratio increased with rising soaking temperature. It's found that in the soaking temperature range of 873-1473 K, high temperature is beneficial to the break-up of large-sized elongated MnS.

\subsection{Effect of Soaking Time}

As seen in Fig. 12, soaking time had a great effect on shape evolution of MnS. With the soaking time of $1 \mathrm{~h}$ or $2 \mathrm{~h}$, most inclusions were still in slender shape. The significant shape change from slender to spherical is identified only when the soaking time reached $3 \mathrm{~h}$ or $4 \mathrm{~h}$, with the number of $\mathrm{MnS}$ samller than $5 \mu \mathrm{m}$ sharply increased. However, there were still some coarse $\mathrm{MnS}$ in large-size which could not break up. Even after 4 hour's soaking, the splitting of these extreme coarse ones had not been observed yet.

The number of small-sized MnS $(<5 \mu \mathrm{m})$ and large-sized ones $(>80 \mu \mathrm{m})$ with soaking time was shown in Fig. 13. It's found that as soaking time increased from 0 hour to 4 hour, the number density of large-sized $\mathrm{MnS}$ decreased from $1.91 / \mathrm{mm}^{2}$ to $0.46 / \mathrm{mm}^{2}$. Meanwhile the number density of small-sized MnS increased dramatically from $1322 / \mathrm{mm}^{2}$ to $5206 / \mathrm{mm}^{2}$. The splitting behavior was very notable.

Shape change of MnS was characterized by the change of mean length, as shown in Fig. 14. It's found that mean length reduced from $5.47 \mu \mathrm{m}$ to $0.67 \mu \mathrm{m}$ with the soaking time increased from 0 hour to 4 hour. It's concluded that soaking time had a great effect on both size and morphology

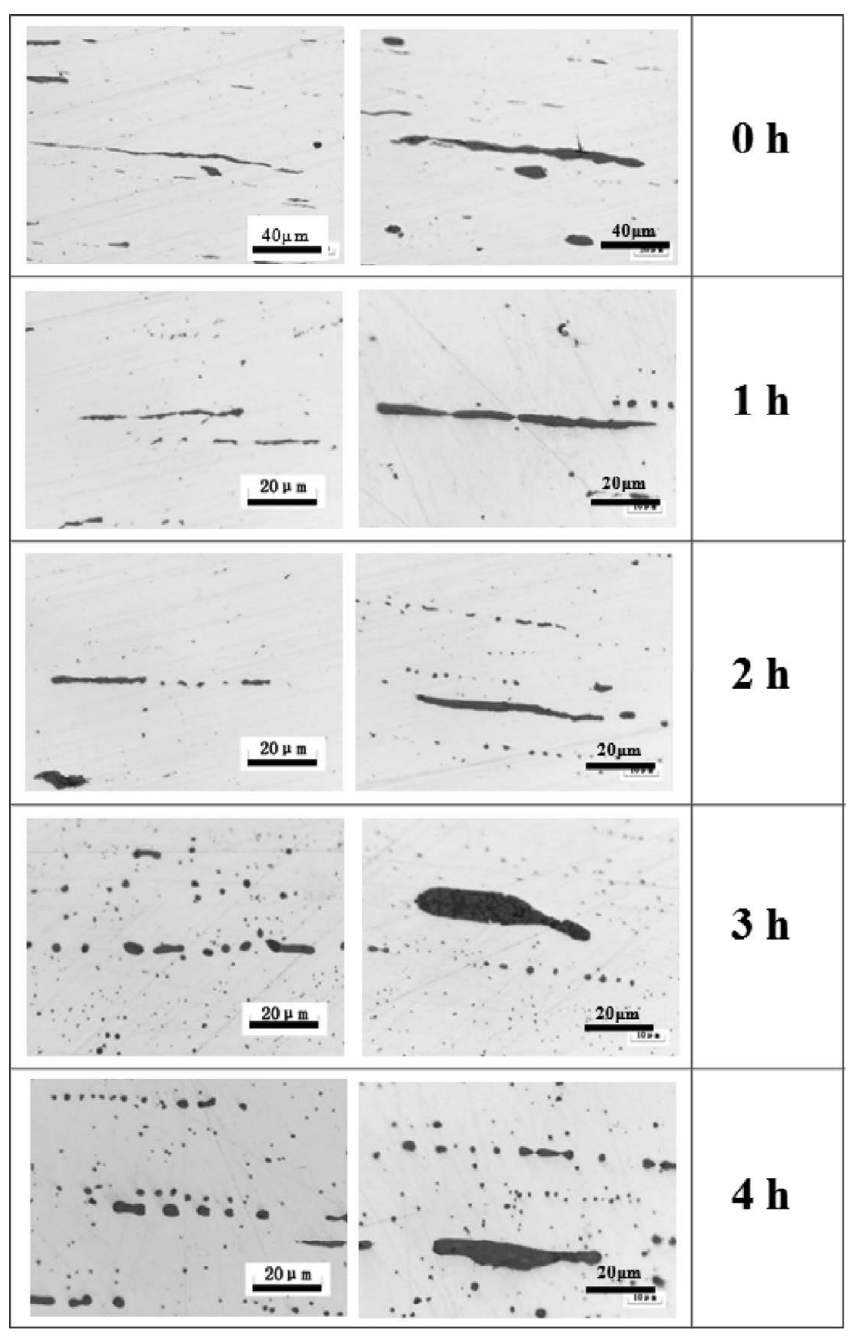

Fig. 12. Typical images of $\mathrm{MnS}$ at different soaking time.

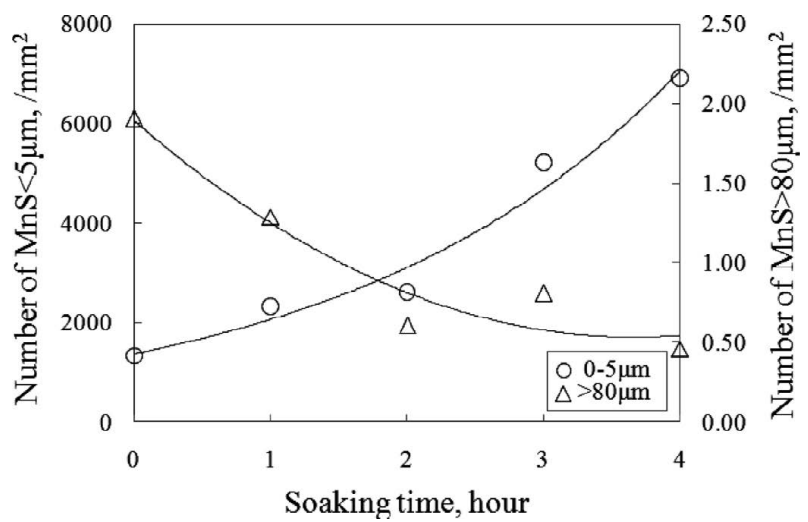

Fig. 13. Number density of $\mathrm{MnS} v s$ soaking time.

changes for large-sized slender $\mathrm{MnS}$.

\subsection{Evolution Mechanisms of Inclusions}

The shape evolution of an elongated $\mathrm{MnS}$ changing to a single spherical particle or splitting to two particles is discussed. Schematic diagrams are listed in Fig. 15.

Shape changes of elongated $\mathrm{MnS}$ are caused by surface diffusion of $\mathrm{Mn}$ atoms and $\mathrm{S}$ atoms. ${ }^{5)}$ Chemical potential on the surface of $\mathrm{MnS}$ is obtained by Gibbs-Thompson relation.

$$
\mu=\mu_{0}+\Omega \gamma K
$$




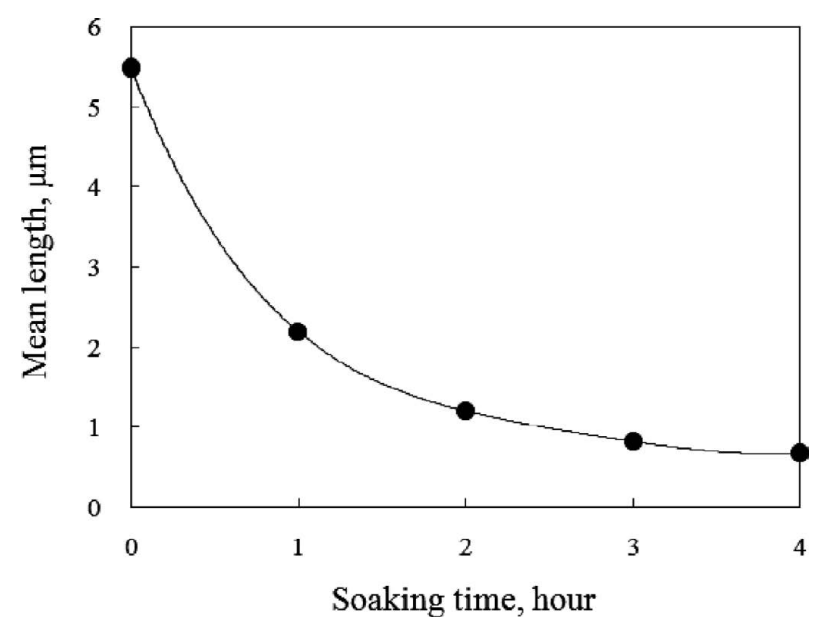

Fig. 14. Mean lengths of MnS vs soaking time.

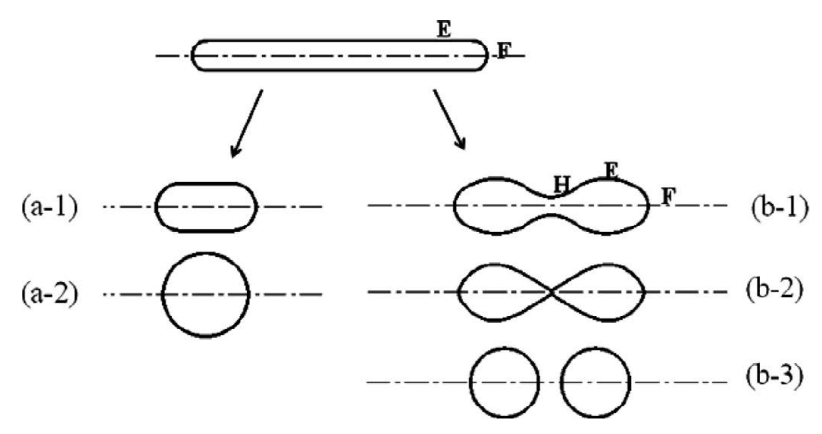

Fig. 15. Schematic diagrams of shape evolution for elongated MnS

Where $\mu_{0}$ represents the chemical potential of a flat surface, $\Omega$ is the molecular volume, $\gamma$ is the surface tension and $K$ is the total curvature of the surface at the point of interest.

Point $\mathrm{E}$ is at the flat surface and point $\mathrm{F}$ is at the surface with the curvature radius of $\mathrm{R}_{\mathrm{F}}\left(\mathrm{K}_{\mathrm{E}}<\mathrm{K}_{\mathrm{F}}\right)$. According to Gibbs-Thompson relation, chemical potential at point $\mathrm{E}$ is lower than chemical potential at point $\mathrm{F}$. Because of the potential difference, $\mathrm{Mn}$ atoms and $\mathrm{S}$ atoms at point $\mathrm{F}$ diffuse to point E. Macroscopic reflection is the contraction in length direction. If the length is small, the contraction directly leads to the formation of the spindle, as shown in Fig. 15(a-1). If the length is large, the two ends bulge. There is no time for atoms to diffuse to the center, so it is still flat in the middle part, as shown in Fig. 15(b-1).

Point $\mathrm{H}$ is at the flat floor and point $\mathrm{E}$ is at the bulge, in Fig. $15(\mathrm{~b}-1) . \mu_{\mathrm{H}}$ is smaller than $\mu_{\mathrm{E}}$. So atoms diffuse from point $\mathrm{E}$ to point $\mathrm{H}$ at the rate of $\mathrm{V}_{1}$. At the same time, the tendency of spheroidizion makes $\mathrm{Mn}$ and $\mathrm{S}$ atoms diffuse from point $\mathrm{H}$ to point $\mathrm{E}$ at the rate of $\mathrm{V}_{2}$. (I) When $\mathrm{V}_{1}>\mathrm{V}_{2}$, atoms fill the center part quickly, forming single spindle. (II) When $\mathrm{V}_{1}<\mathrm{V}_{2}, \mathrm{Mn}$ and $\mathrm{S}$ atoms in the center diffuse to two bulges, as shown in Fig. 15(b-2). Then, it splits and spheroidizes into two distinct particles, as shown in Fig. 15(b-3). In our experiment, many $\mathrm{MnS}$ shaped like the ones in Fig. 15 were observed (see Fig. 16).

In order to clarify the diffusion mechanism, mathematical deduction combind with experimental results are carried out.

From the above explanation, it's known that slender MnS can change into two bulges due to the chemical potential difference, as shown in Fig. 17. As a result, change in the

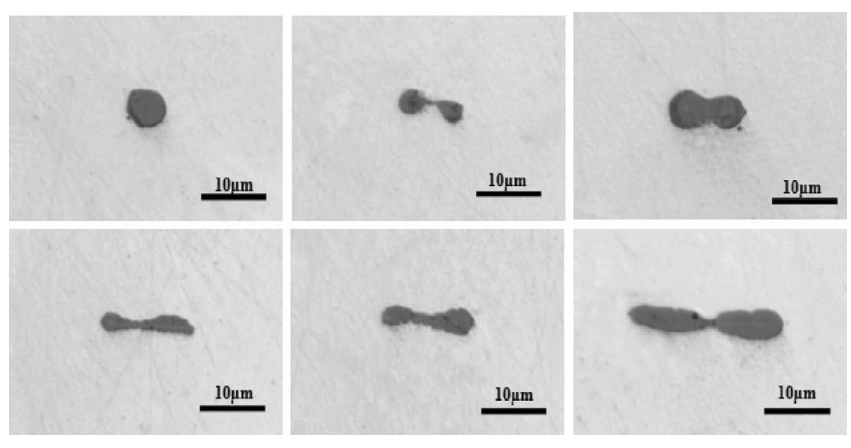

Fig. 16. Shape evolution for slender $\mathrm{MnS}$ observed in present study.

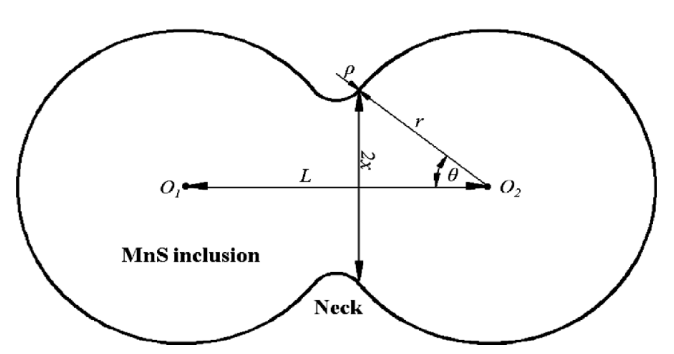

Fig. 17. Schematic diagrams of split process for $\mathrm{MnS}$ inclusion.

distance between the centers of two bulges $(\Delta \mathrm{L})$ satisfies the following geometric relationship.

$$
\frac{\Delta L}{L}=\frac{[(r+\rho) \cos \theta]-r}{r}
$$

Where, $L$ is the distance between centers of the two bulges, $\Delta L$ is the change in the distance between the two centers, $r$ means the radius of $\mathrm{MnS}$ inclusion and $\rho$ is the radius of the neck.

If $\theta$ is small enought, $\cos \theta$ approximately equals to one.

$$
\rho=r(1-\cos \theta)=2 r \sin ^{2} \frac{\theta}{2} \approx \frac{x^{2}}{2 r}
$$

Combined Eq. (3) with Eqs. (4), (5) was obtained.

$$
\frac{\Delta L}{L}=\frac{x^{2}}{4 r^{2}}
$$

Mass transfer in present study is assumed to be controlled by diffusion alone. Kuczynski has derived diffusioncontrolled kinetic equation for stable neck growth. ${ }^{15}$ )

$$
\left(\frac{x}{r}\right)^{n}=F(T) \times T^{-m} \times t
$$

Where $F(T)$ is the function of temperature. $\mathrm{m}$ and $\mathrm{n}$ are constants, which are only relevant to diffusion type.

Introducing Eqs. (5) to (6), (7) can be obtained as follows:

$$
\frac{\Delta L}{L}=\frac{1}{4} \times\left(F(T) \times T^{-m} \times t\right)^{\frac{2}{n}}
$$

Logarithmic equation on both sides, it's obtained

$$
\lg \left(\frac{\Delta L}{L}\right)=\lg \frac{1}{4}+\frac{2}{n} \lg \left[\left(F(T) \times T^{-m}\right)\right]+\frac{2}{n} \lg \frac{t}{4}
$$

From Eq. (8), it's known that $\lg (\Delta L / L)$ shows a linear correlation with $\lg (t / 4)$ at a fixed temperature. 


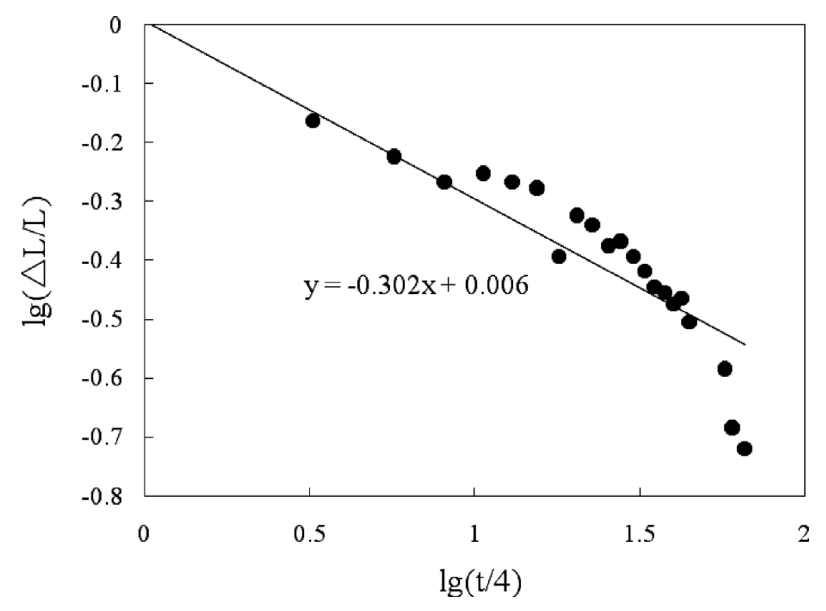

Fig. 18. $\lg (\Delta \mathrm{L} / \mathrm{L})$ vs $\lg ($ time $/ 4)$.

Relation between the measured logarithm of $(\Delta L / L)$ and $(t / 4)$ in soaking experiments at $1273 \mathrm{~K}$ in section 3.4 is given as Fig. 18, as indicated by solid circles. It could be seen that simple linear relation existed between the two with a slope of about -0.302 , whose absolute value is 0.302 .

So $n=7$ is derived from Eq. (8). According to Kuczynski's research, ${ }^{15)}$ it indicated that surface diffusion was the main diffusion type for shape change of elongated $\mathrm{MnS}$.

\section{Conclusions}

(1) In-situ observation experiments showed that largesized elongated $\mathrm{MnS}$ could split up and spheriodize at high temperature.

(2) The combined in-situ experiments and theoretical analysis indicated that shape evolution of elongated largesized MnS were (1) axial contraction (2) expansion and contraction in radial direction (3) spheroidization.

(3) Heating rate has a great effect on shape variation of slender MnS. With heating rate rose from 0.5 to $2 \mathrm{~K} / \mathrm{s}$, the number of split MnS decreased and the maximum aspect ratio increased. When heating rate exceeded $6 \mathrm{~K} / \mathrm{s}$, slender $\mathrm{MnS}$ kept unchanged. Slow heating rate would facilitate the shape control of large-sized elongated $\mathrm{MnS}$.

(4) Regarding soaking temperature, the break-up of slender MnS didn't occure until $1273 \mathrm{~K}$. When reached $1473 \mathrm{~K}$, the splitting degree was more remarkable than at $1273 \mathrm{~K}$. It's indicated that high soking temperature is beneficial to obtain spindle-liked $\mathrm{MnS}$ with small sizes.

(5) For soaking time, when extended from $0 \mathrm{~h}$ to $4 \mathrm{~h}$, the number density of $\mathrm{MnS}$ larger than $80 \mu \mathrm{m}$ decreased from $1.91 / \mathrm{mm}^{2}$ to $0.46 / \mathrm{mm}^{2}$, while that of MnS smaller than $5 \mu \mathrm{m}$ increased from $1322 / \mathrm{mm}^{2}$ to $6913 / \mathrm{mm}^{2}$. The obvious shape change from slender to spherical was identified only when the soaking time exceeds $3 \mathrm{~h}$. It's indicated that soaking at $1473 \mathrm{~K}$ for $3 \mathrm{~h}$ or $4 \mathrm{~h}$ is good for shape and size control of large-sized slender MnS.

\section{REFERENCES}

1) J. W. Flowers and S. P. Karas: J. Appl. phys., 38 (1967), 1085

2) D. Gnanamuthu, T. Z. Kattamis, M. C. Flemings and R. Mehrabian: Metall. Trans., 5 (1974), 2557.

3) P. C. Wilson, Y. V. Murty, T. Z. Kattamis and R. Mehrabian: Met Technol., 2 (1975), 241.

4) Y. V. Murty, J. E. Morral, T. Z. Kattamis and R. Mehrabian: Metall. Trans. A, 6 (1975), 2031.

5) Y. V. Murty, T. Z. Kattamis, R. Mehrabian and M. C. Flemings: Metall. Trans. A, 8 (1977), 1275.

6) W. H. Mcfarland and J. T. Cronn: Metall. Trans. A, 12 (1981), 916.

7) M. Nishida, T. Kato and T. Tanaka: Tetsu-to-Hagané, 67 (1981), 1539.

8) X. J. Shao, X. H. Wang, W. J. Wang, C. W. Yang, F. X. Huang, M. Jiang and X. X. Deng: Trans. Mater. Heat Treat., 31 (2010), 80.

9) X. J. Shao, X. H. Wang, W. J. Wang, F. X. Huang and M. Jiang: $J$. Univ. Sci. Technol. B., 32 (2010), 570.

10) F. A. Nichols: J. Mater. Sci., 11 (1976), 1077.

11) F .A. Nichols and W. W. Mullins: Trans. Metall. Soc. AIME, 233 (1965), 1840.

12) X. J. Shao, M. Jiang and X. H. Wang: CAMP-ISIJ, 24 (2011), 521

13) G. Seiber: Mem. Sci. Rev. Met., 61 (1964), 413.

14) E. A. Brandes: Smithells Metals Reference Book, Butterworths, London, (1983), 1317.

15) G. C. Kuczynski: Trans. AIME, 185 (1949), 169. 